\title{
Recrystallization Effect and Electric Flame-Off Characteristic of Thin Copper Wire
}

\author{
Fei-Yi Hung*, Yuan-Tin Wang, Li-Hui Chen and Truan-Sheng Lui \\ Department of Materials Science and Engineering, National Cheng Kung University, Tainan, Taiwan 701, R. O. China
}

Compared with gold wire, copper wire is cheaper and possesses lower cost, greater strength and better electrical conductivity, and therefore is becoming more commonly used. But the lower ductility and oxidation undermine the reliability of copper wire bonding, making the wire susceptible to breaking. In the present study, the annealed effect (at $150-250^{\circ} \mathrm{C}$ for 1 hour) on the tensile mechanical properties of copper wires with $\phi=25 \mu \mathrm{m}$ ( 1 mil) was investigated. In addition, the microstructural characteristics and the mechanical properties before and after an electric flame-off (EFO) process were also studied.

Experimental results indicate that with annealing temperatures of more than $200^{\circ} \mathrm{C}$, the copper wires possessed a fully annealed structure, the tensile strength and the hardness decreased, and the elongation was raised significantly. Through recrystallization, the matrix structure transferred from long, thin grains to equiaxed grains and a few annealed twins. The microstructures of the free air ball (FAB) of the variation annealing wires after an EFO process were column-like grains. The column-like grains grew from the heat-affected zone (HAZ) to the Cu ball, and the preferred orientation was $\langle 100\rangle$. Under the thermal effect of EFO, the necks of the Cu balls underwent recrystallization and the grain growth was induced. Additionally, the decreased hardness and the strength of the HAZ resulted in the breakage sites of the EFO wires being in the HAZ near the Cu balls. [doi:10.2320/matertrans.47.1776]

(Received February 9, 2006; Accepted May 11, 2006; Published July 15, 2006)

Keywords: wire bonding, copper, electric flame-off (EFO), recrystallization

\section{Introduction}

Thermosonic ball bonding is one of the preferred processes of electronic packaging to connect a semiconductor chip and a lead frame by a thin metal wire. Gold wire and copper wire are the preferred interconnect materials to bond with the aluminum metallized wafer pads during this process. ${ }^{1,2)}$ Gold is expensive, and the electrical conductivity and thermal conductivity of gold is lower than that of copper. ${ }^{3,4)}$ In addition, the inherent properties of higher tensile strength, hardness and stiffness of copper as well as its cost effectiveness compared to gold, have made it a preferred alternative. ${ }^{3,5)}$

In general, three factors affect the reliability of copper wire bonding ${ }^{3,6)}$ namely: 1 . Oxidation causes unusual bonding, 2. The lower strength of the annealed wire results in the breakage, 3 . The high hardness of copper wire can damage chips during the wire compressing process. As-drawn copper wire possesses higher strength and hardness, however its lower ductility reduces the reliability of bonding. So, the annealing treatment of as-drawn copper wire is very important. Many studies ${ }^{2,3,6)}$ have discussed the process variables such as bonding force, temperature and electric flame-off (EFO), etc. However, the recrystallization effect in the microstructure and the relevant mechanical properties of the thin copper wires $(\phi=25 \mu \mathrm{m})$ have still not been examined. In addition, because the breakage sites of EFO wires are in the neck between HAZ and the ball, it's clear that the breakage result from the structure of the neck zones and stress affecting the breakage sites. ${ }^{2,6,7)}$ Thus, this paper not only investigated the mechanical properties of copper wire by varying the annealing temperature (at $150-250^{\circ} \mathrm{C}$ for 1 hour), but also investigated the fracture mechanism of the free air ball (FAB) with various annealing wires using EFO process.

*Corresponding author, E-mail: fyhung@mail.mse.ncku.edu.tw
Table 1 ICP analysis of the chemical composition of $\mathrm{Cu}$ wire (ppm).

\begin{tabular}{ccccccccc}
\hline $\mathrm{Si}$ & $\mathrm{Fe}$ & $\mathrm{Mn}$ & $\mathrm{Ni}$ & $\mathrm{Zn}$ & $\mathrm{Ti}$ & $\mathrm{Pb}$ & $\mathrm{Sn}$ & $\mathrm{Cu}$ \\
\hline 0.45 & 0.05 & 0.22 & 0.08 & 0.10 & 0.06 & 0.53 & 0.07 & Bal. \\
\hline
\end{tabular}

\section{Experimental Procedure}

\subsection{Annealing treatment and electric flame-off process}

A copper ingot of $99.99 \%$ purity was drawn to thin copper wire with diameter $\phi=25 \mu \mathrm{m}$ (ICP analysis of the chemical composition is shown in Table 1). Four temperatures, 100, 150,200 and $250^{\circ} \mathrm{C}$, were chosen for the vacuum $\left(10^{-3} \mathrm{~Pa}\right)$ annealing in the as-drawn wire. The annealing time for the as-drawn wires was fixed at 1 hour, and followed by air cooling to room temperature. The melting of the wire tip was controlled by EFO process using the thermosonic wire bonder machine. To prevent oxidation during the ballformation process, a $95 \%$ nitrogen- $5 \%$ hydrogen gas mixture was maintained at a flow rate of $1 \mathrm{~L} \cdot \mathrm{min}^{-1}$.

\subsection{Tensile testing and micro-hardness analysis}

To understand the effects of annealing on the mechanical property of the $\mathrm{Cu}$ wire, both annealed and unannealed wires were subjected to tensile testing, after which the relation between the mechanical properties and recrystallization was investigated. In addition, the neck of each $\mathrm{Cu}$ ball with various annealing wires was also subjected to tensile testing to examine the characteristics of HAZ. The testing method used a plate clamp to fix the free air ball (FAB), while the wire tip was fixed using a tongs-like clamp. A schematic illustration of the tensile test is shown in Fig. 1. The copper wire had a diameter of $\phi=25 \mu \mathrm{m}$ and length of $10 \mathrm{~cm}$. In addition, the tensile test results of each wire had a constant strain rate of $2.54 \mathrm{~cm} / \mathrm{min}$ and each analysis datum is the average of 20 test results (including the neck of the $\mathrm{Cu}$ ball). With an aim to understanding the tensile deformation 


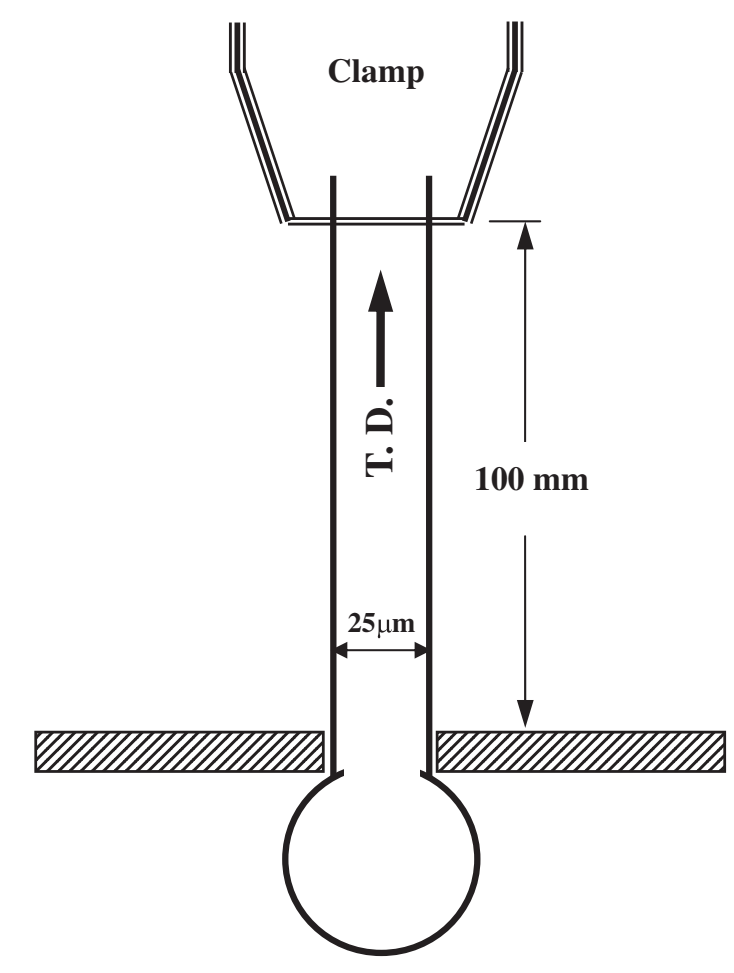

Fig. 1 The schematic illustration of the tensile testing for the neck.

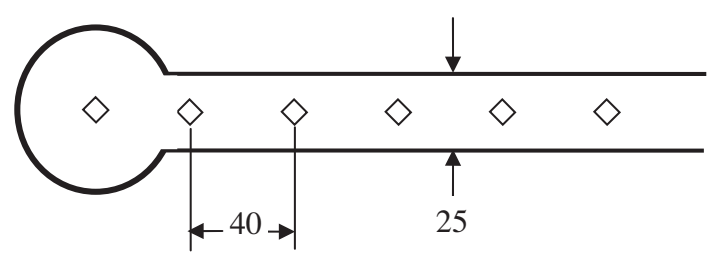

Fig. 2 The schematic illustration of the micro-hardness measuring (unit: $\mu \mathrm{m})$.

mechanism of the wire, the tensile fracture characteristics were observed using OM and SEM.

Micro-hardness measurements were performed on a cross section of the unannealed copper wire, the ball and the HAZ. The force was $5 \mathrm{~g}$ and the holding time was $10 \mathrm{sec}$. A schematic illustration (include electric flame-off wire) of the hardness testing is shown in Fig. 2. Each analysis datum is the average of at least 10 test results.

\section{Results and Discussion}

\subsection{Effect of annealing on the microstructure and the mechanical properties of copper wire}

The cross section microstructures of the annealed and unannealed wires are shown in Fig. 3. The structure of the asdrawn wire contained long, thin grains parallel to the direction of unannealing (see Fig. 3(a)). Figure 3(b) shows the structure of the $100^{\circ} \mathrm{C}$ annealed wire. It is similar to Fig. 3(a). A few equiaxed grains were found in the $150^{\circ} \mathrm{C}$ annealed wire (see Fig. 3(c)). The microstructures of both the 200 and $250^{\circ} \mathrm{C}$ annealed wires are shown in Figs. 3(d) and (e), revealing the two copper wires contained fully annealed equiaxed grains and a few annealed twins.
Figures 4 and 5 show a comparison of the tensile test results of the copper wires with various annealing temperatures. The $100^{\circ} \mathrm{C}$ wire is similar to the unannealed wires, and their elongation (T. E.) was very low at less than $1 \%$. When the annealing temperature was $200^{\circ} \mathrm{C}$, both U.T.S. and Y.S. decreased and the elongation raised significantly $(\sim 15 \%)$. At an even higher annealing temperature, the results of the $250^{\circ} \mathrm{C}$ wire were still similar to those of the $200^{\circ} \mathrm{C}$ wire. Notably, the $200^{\circ} \mathrm{C}$ wire possessed a fully annealed structure (see Fig. 3(d)) and higher ductility. It can be inferred from what has been said above that a temperature of $\sim 200^{\circ} \mathrm{C}$ is probably the recrystallization temperature of the as-drawn wire. To investigate further, micro-hardness was measured on the cross section of the copper wires, as shown in Fig. 6. The evidence reveals that the hardness had a tendency towards strength. The hardness of the annealed wires had reduced significantly compared with the unannealed wire. So, it is safe to say that the recrystallization temperature of the unannealed wire was at $\sim 200^{\circ} \mathrm{C}$.

\subsection{Observations of electric flame-off characteristics and tensile analysis of the $\mathrm{Cu}$ ball}

Figure 7 shows the appearance of the free air ball (FAB) using the electric flame-off (EFO) process. In fact, a good FAB should be about twice as large in diameter as the wire and should possess a ball shape. ${ }^{7)}$ The FAB in the atmosphere in Fig. 7(a) has an imperfect ball shape and a rough surface because of serious oxidation. Figure 7(b) shows the appearance of the ball in the gas mixture $\left(95 \% \mathrm{~N}_{2}+5 \% \mathrm{H}_{2}\right)$. The ball possesses a better shape, smooth surface and appropriate dimensions. Clearly, the protective gas mixture provided much assistance.

To understand the tensile strength of the neck, the copper balls of the unannealed wire and the annealed wires were measured, as shown in Fig. 8. The EFO process made the neck strength of the balls lower than that of the without-EFO wires (see Fig. 4). In addition, the strength of the necks of the $\mathrm{Cu}$ balls had a tendency to increase with increasing the annealing temperature. The evidence reveals that the balls of the fully annealed wires (temperature above $200^{\circ} \mathrm{C}$ ) possessed greater neck-strength. Notably, the breakage site of the EFO wires were at the back of the neck, not at the back of the ball (see Fig. 9), revealing that structural variations from the EFO process affected the deformation resistance of the neck zone.

\subsection{The electric flame-off (EFO) mechanism and break- age site analysis}

The cross section microstructures of the $\mathrm{FAB}$ of the $200^{\circ} \mathrm{C}$ annealed wires were shown in Fig. 10(a). The ball structure contained the isotropy column-like grains, while the grains of the neck had grain growth induced by heat. Both the FABs of the unannealed wire and the $150^{\circ} \mathrm{C}$ annealing wires were observed, as shown in Figs. 10(b)(c). In addition to the isotropy column-like grains, the necks of the $\mathrm{Cu}$ balls underwent recrystallization during the EFO process. Through this recrystallization, the matrix structure transferred from its original long-thin grains (Figs. 3(a)(c)) to equiaxed grains and a few annealed twins.

The microstructures of the wire after the electric flame-off 


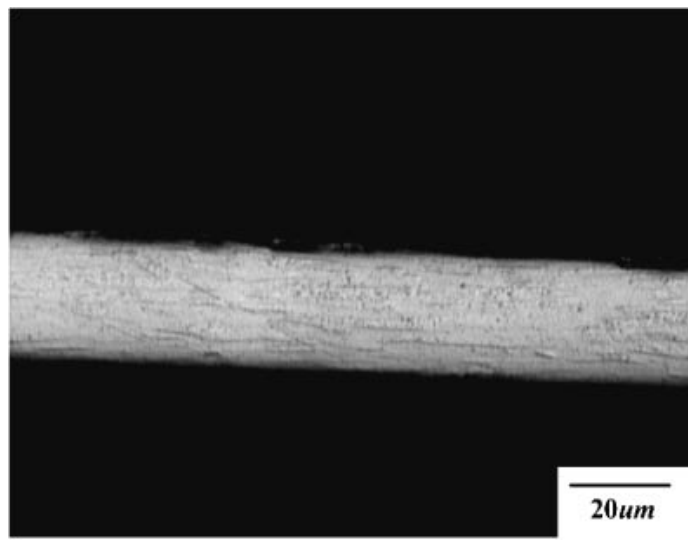

(a)

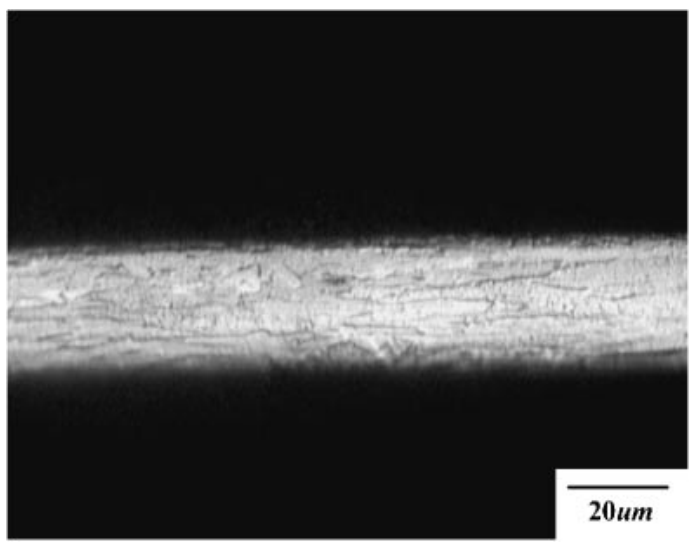

(c)

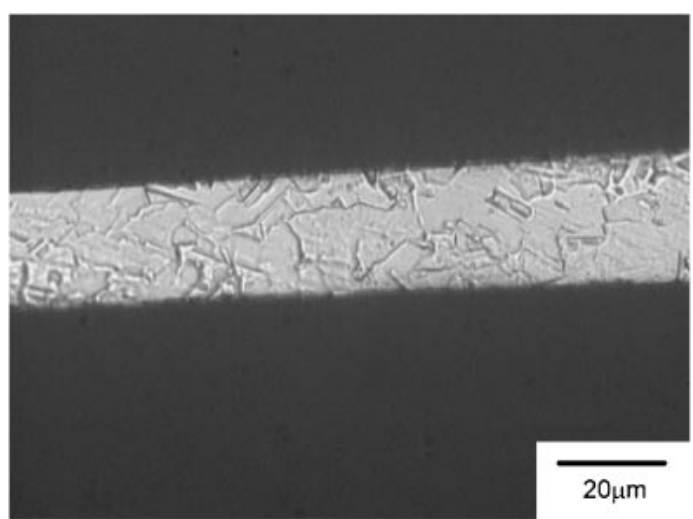

(e)

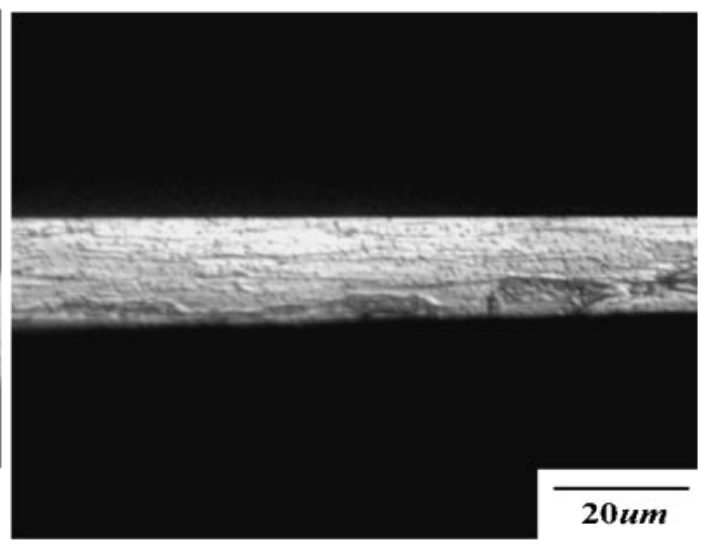

(b)

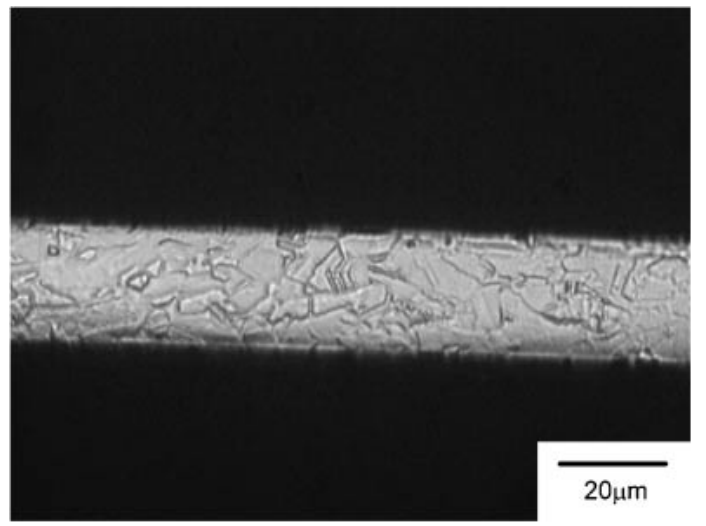

(d)

Fig. 3 Microstructures of the annealed wires at different temperature for 1 hour: (a) unannealed, (b) $100^{\circ} \mathrm{C}$, (c) $150^{\circ} \mathrm{C}$, (d) $200^{\circ} \mathrm{C}$ and (e) $250^{\circ} \mathrm{C}$.

(EFO) can be divided into a solidification zone (i.e., the copper balls), a heat-affected zone (HAZ) induced by the EFO, and an unaffected zone. Figure 10 shows that the continuous interfaces with no void were found between the balls and the heat affect zone. So, it is safe to say that the column-like grains of the ball grew from the HAZ (i.e., the without-solidification wire) to the melting ball. The normal direction of the twinning plane of a fcc twin is $\langle 111\rangle$ and the preferred orientation of the solidification dendrite is $\langle 100\rangle$. The included angle of the above-mentioned two directions was $54^{\circ}$ according to the following formula.

$$
\cos \theta=\frac{N_{1} \cdot N_{2}}{\left|N_{1}\right|\left|N_{2}\right|}
$$

We then measured the included angle between the growndirection of column-like grain and the normal direction of the twinning plane to be about $54^{\circ}$ (see Fig. 10(b)). This evidence also confirms that the preferred orientation of the isotropy column-like grains was $\langle 100\rangle$.

Additionally, micro-hardness analysis of the $200^{\circ} \mathrm{C}$ annealed wire after EFO revealed that the neck of the FAB (i.e., HAZ) had the lowest value (see Fig. 11). Also, it can be seen 


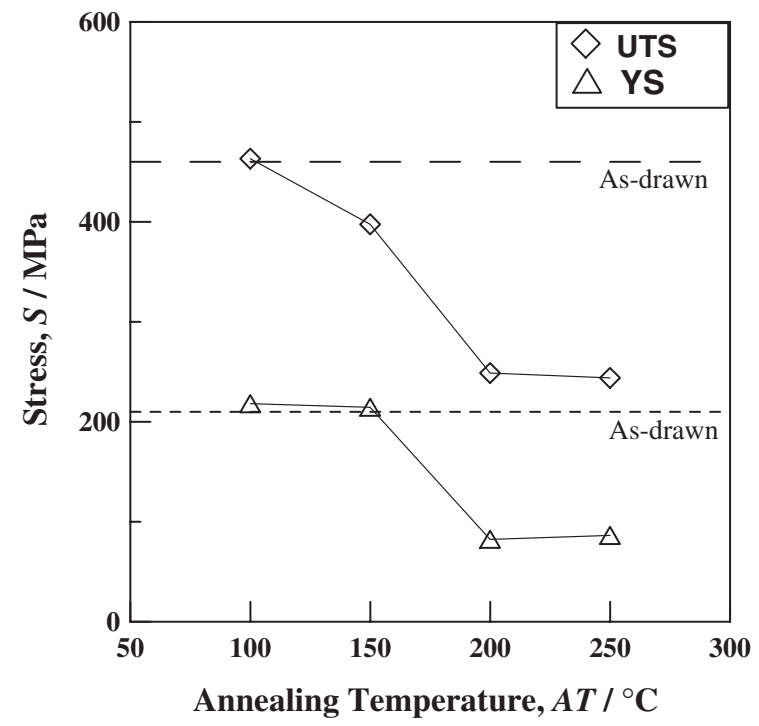

Fig. 4 Tensile strength of wires with various annealing temperature.

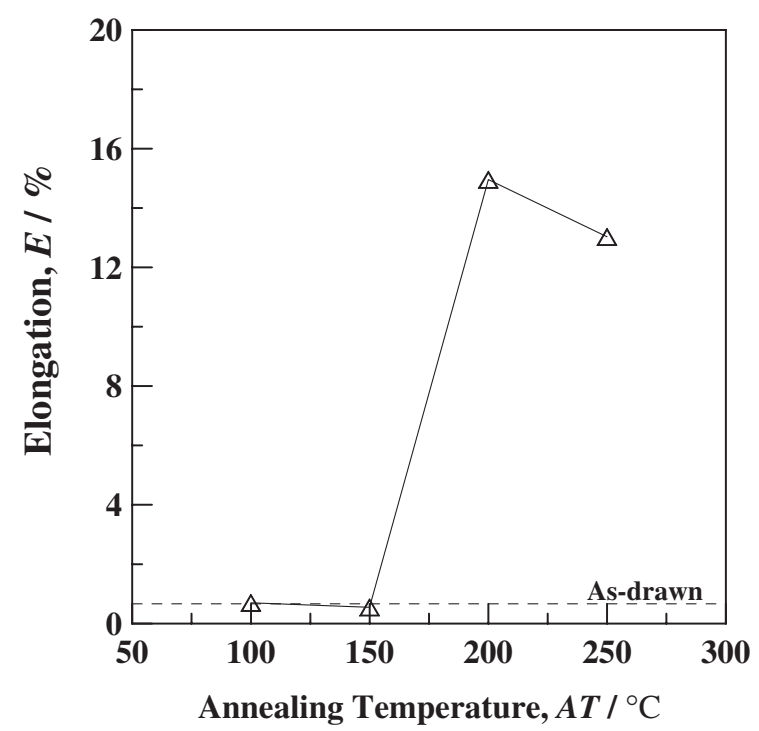

Fig. 5 Elongation of copper wires with various annealing temperature.

from Fig. 11 that the hardness had a tendency to increase when this zone was far away from the HAZ. Comparing the $200^{\circ} \mathrm{C}$ data of Fig. 6 with Fig. 11, the hardness increased significantly with lengths of less than $300 \mu \mathrm{m}$. Notably, the unannealed wire and the annealed wires also experienced changes similar to these mentioned above. So, it can be inferred that the HAZ had a length of about $300 \mu \mathrm{m}$. According to Fig. 9, the breakage site of the EFO wires should be in the HAZ. This is one reason why the breakage sites occurred within $300 \mu \mathrm{m}$ of the neck.

The ultimate tensile strength (UTS) of both the neck and the without-EFO wire were compared, as shown in Fig. 12. The strength of the neck was lower than that of the withoutEFO wires. This is because the heat effect induced by the EFO process reduced the deformation resistance of the HAZ. In addition, the breakage site of the EFO wires occurred in the HAZ. Clearly, the deformation resistance of the HAZ was lower than that of the neck of the solidification ball. Even

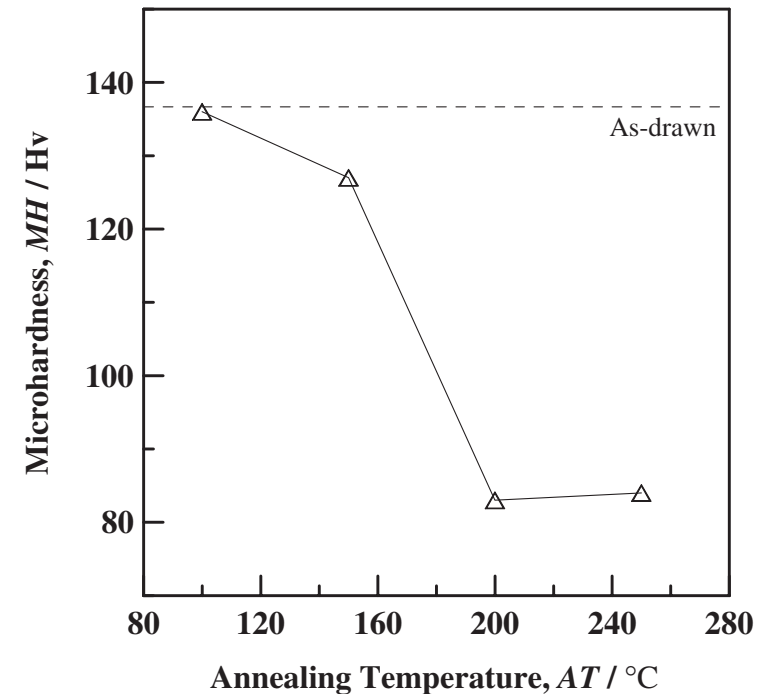

Fig. 6 Micro-hardness of wires with various annealing temperature.

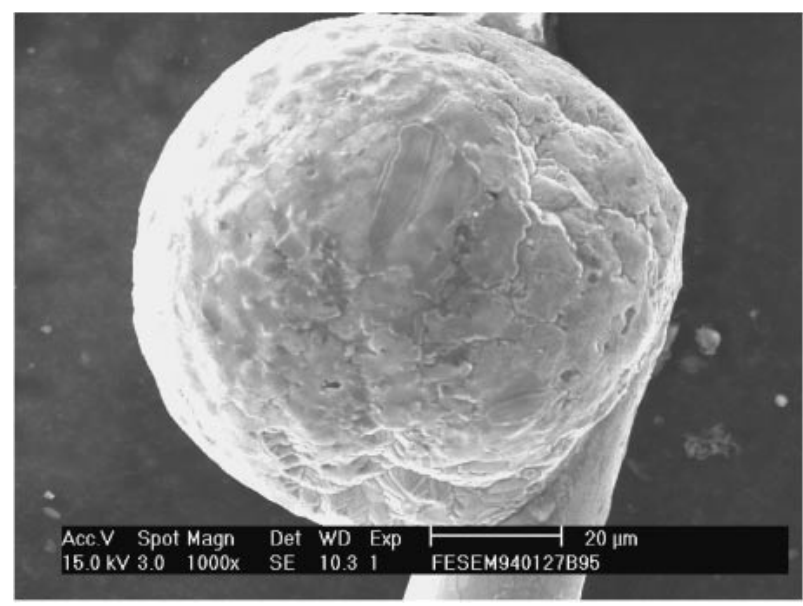

(a)

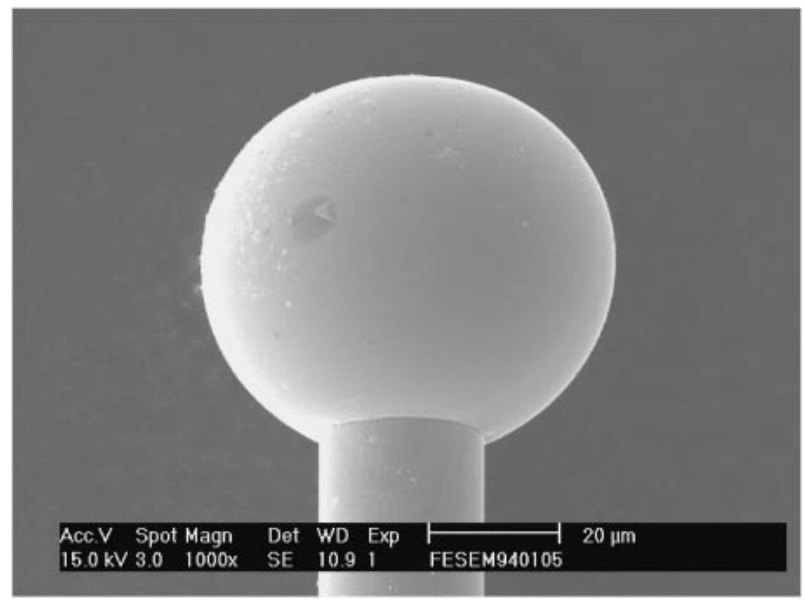

(b)

Fig. 7 SEM photos of the FAB after the EFO process: (a) at the atmosphere, (b) $95 \% \mathrm{~N}_{2}+5 \% \mathrm{H}_{2}\left(200^{\circ} \mathrm{C}\right.$ annealed wire).

through the neck of the solidification ball experienced a stress concentration effect and the nucleus of the column-like grain, its deformation resistance was still higher than the HAZ. 


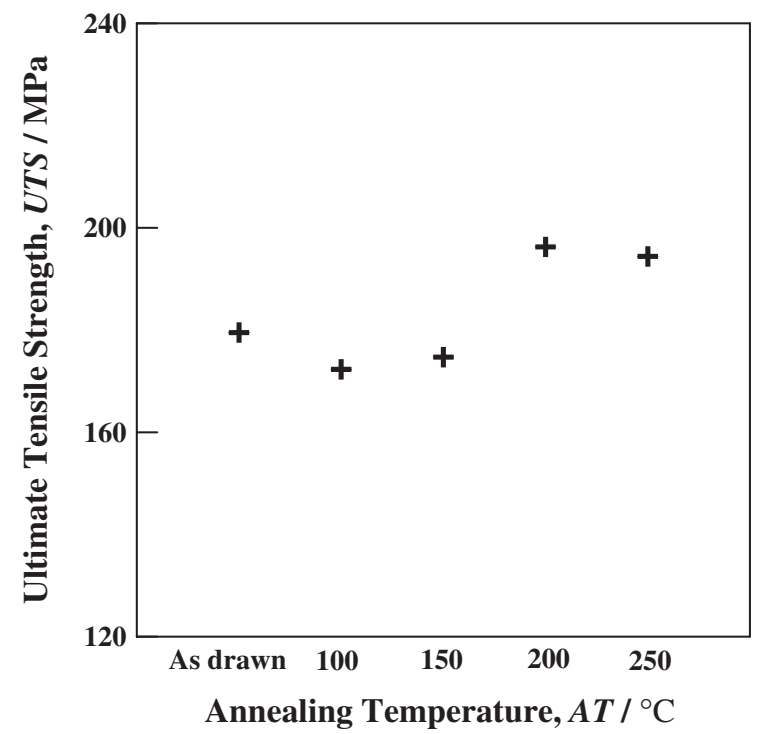

Fig. 8 The ultimate tensile strength (UTS) of the neck of balls.

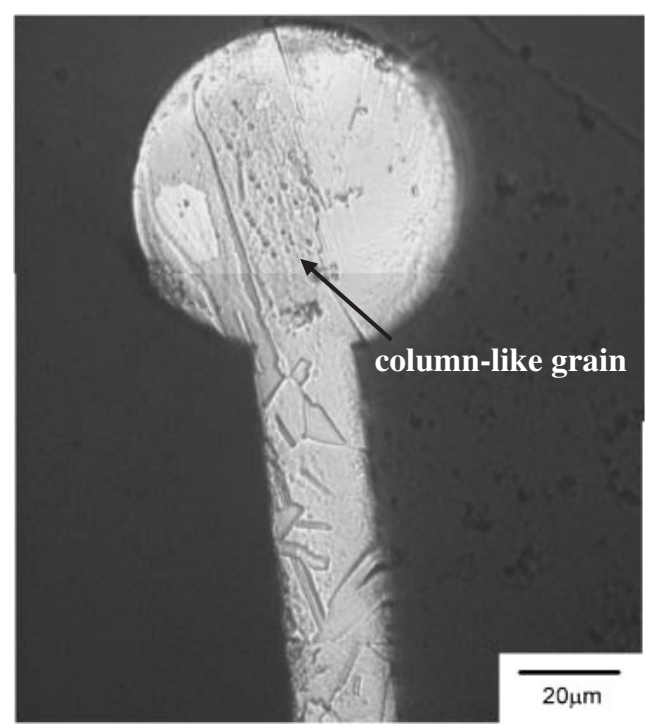

(a)

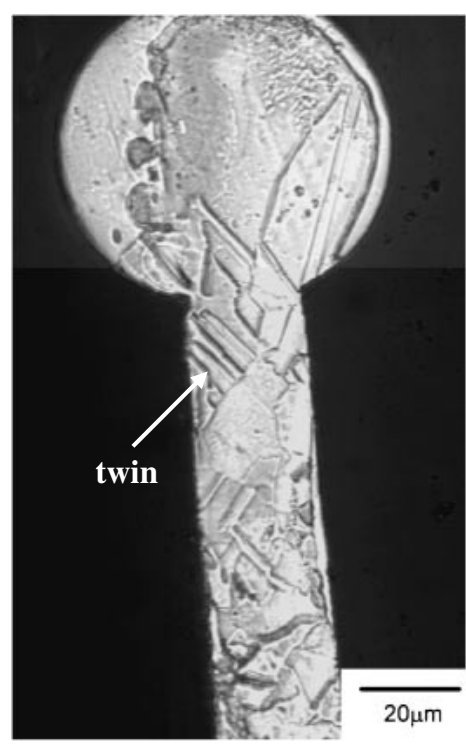

(c)

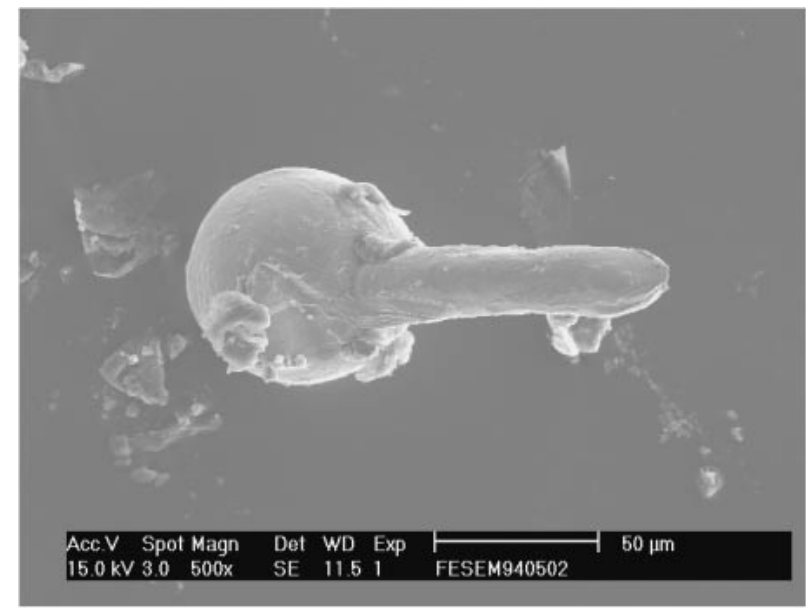

Fig. 9 Tensile fracture feature of the EFO wires (Take $150^{\circ} \mathrm{C}$ annealed wire for example).

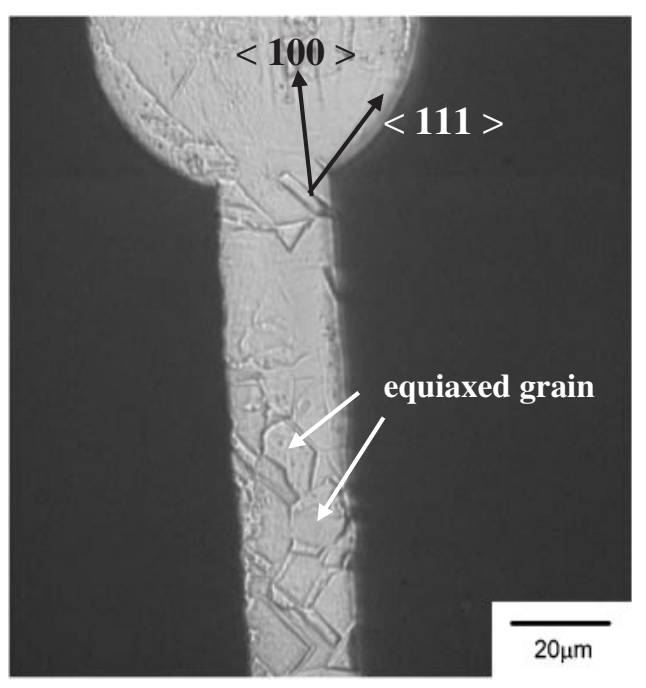

(b)

Fig. 10 The cross section of the FABs: (a) $200^{\circ} \mathrm{C}$, (b) un-annealed and (c) $150^{\circ} \mathrm{C}$. 


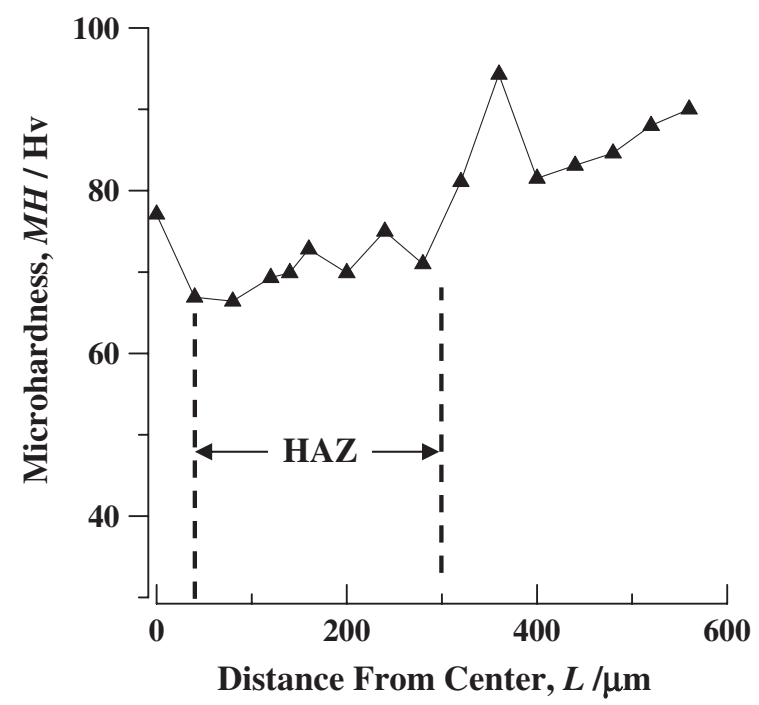

Fig. 11 Micro-hardness of the $200^{\circ} \mathrm{C}$ annealed wire after EFO process (the origin of the cross axle is the center of FAB).

\section{Conclusions}

(1) The recrystallization temperature of the unannealed wire was $\sim 200^{\circ} \mathrm{C}$. The annealed wires $\left(\geq 200^{\circ} \mathrm{C}\right)$ contained fully annealed equiaxed grains with a few annealed twins. The tensile strength and the hardness had decreased, while the elongation had increased significantly.

(2) The strength of the HAZ induced by the EFO process had a tendency to increase with increasing the annealing temperature. The tensile breakage sites of the EFO wires were in the HAZ. The nuclei of column-like grains in the $\mathrm{Cu}$ ball existed in the HAZ and the preferred orientation of the isotropy column-like grains was $\langle 100\rangle$.

\section{Acknowledgements}

The authors are grateful to the Chinese National Science

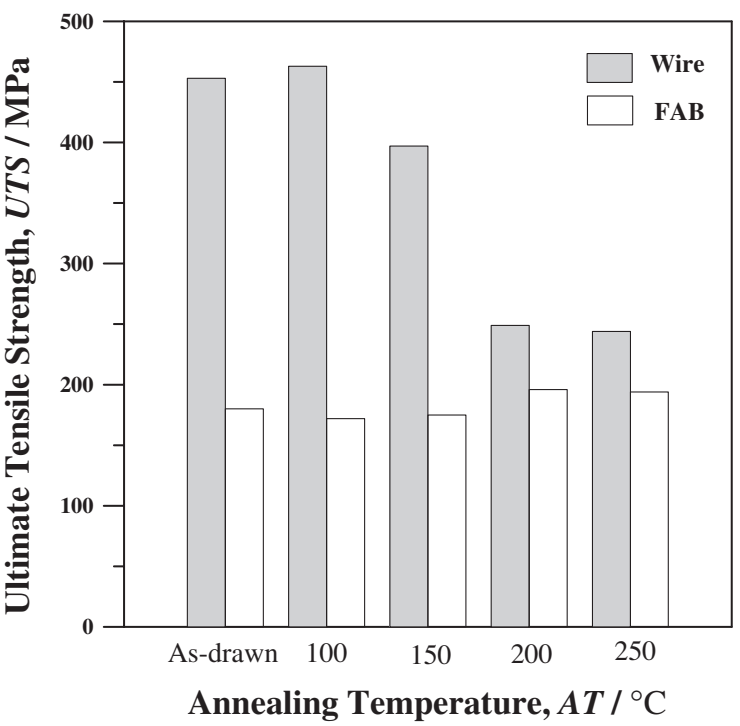

Fig. 12 The comparison of the ultimate tensile strength: the neck of balls and the without-EFO wires.

Council for its financial support (Contract: NSC 95-2216-E006-006-CC3).

\section{REFERENCES}

1) F. Wulff, C. D. Breach and K. Dittmer: J. Mater. Sci. Lett. 22 (2003) 1373-1376.

2) N. Murali, N. Srikanth and Charles J. Vath III: Mater. Res. Bull. 38 (2003) 637-646.

3) N. Srikanth, S. Murali, Y. M. Wong and Charles J. Vath III: Thin Solid Films 462 (2004) 339-345.

4) Properties and Selection: Nonferrous Alloys and Pure Metals, Metals Handbook, Ninth Edition, Volume 2.

5) H. M. Ho, W. Lam, S. Stoukatch, P. Ratchev, Charles J. Vath III and E. Beyne: Microelectron. Reliab. 43 (2003) 912-923.

6) S. Murali, N. Srikanth and Charles J. Vath III: Mater. Charact. 50 (2003) 39-50.

7) A. Saboui: IEEE/CHMT IEMT Symposium, (1991) 75-79. 